Book Review

\title{
LEARNING IN LANDSCAPES OF PRACTICE: BOUNDARIES, IDENTITY, AND KNOWLEDGEABILITY IN PRACTICE-BASED LEARNING
}

edited by Etienne Wenger-Trayner, Mark Fenton-O'Creevy, Steven Hutchinson, Chris Kubiak, Beverly Wenger-Trayner

I came to this book familiar with (but not wholly well-versed in) the work of Etienne Wenger and therefore curious about the developments in his previously proposed themes of communities of practice and social learning through this new multi-editor text. As a teacher educator and researcher in the field of professional learning the book offered an opportunity to extend my knowledge base and reflect on the conceptualisations of learning by other practitioners through their own and other's eyes. It also felt like a genuine invitation into other lives and ideas. The illustrative elements of the book provide windows into the worlds of teachers, social workers, academics, arts practitioners, leaders, health and medical practitioners, childminders, business-people and students amongst others. These are real examples, gathered by the authors through participant engagement in research and professional development structures.

Without doubt the book fascinates. There is substantial space given to stories of learning in practice. Even without engaging at a theoretical level with the conceptual frameworks and lenses offered the stories create reflections on experience which are 
thought-provoking, evocative and illustrative. Their contexts and subjects are diverse. They focus on learners and those who create and manage learning opportunities. They include narratives which interrogate the relationships between individuals and systems. While sharp and interesting contrasts emerge in lives of learners, the stories have a common denominator in the central significance of learners' practices and the landscapes in which they are located. As would be expected the relationships between work and learning and the nature of practice that forges these relationships is explored. Even the practices underpinning the writing of the book are reflected upon - offering the reader another layer of insight into an often opaque academic practice of combined and collected scholarship.

The stories are framed in the theory building process underpinning the book. The metaphor of landscapes for contexts of practice is introduced, sustained and developed. As a former geography teacher I found this metaphor to be vibrant and intellectually engaging. The sense of movement or journeys across landscapes, the fact that landscapes themselves evolve and are influenced by local and more distant forces makes sense. Extending the construct to boundaries between landscapes builds the theory and allows the conceptualisation of boundary objects and brokering in practice-based learning to be explored. At times the reader may need to engage with a degree of imagination, reading between the lines to create meaning as the ideas come thick and fast. This depth and richness however offers huge potential for re-visiting the book. Taking ideas and relating them to one's own cases of practice, framing and re-framing learning experiences, hurdles and destinations. 
The authors provide new means though which knowledge and knowledgeability can be conceptualised. While they offer stories the book is not whimsical or simply documentary. It does not offer a theoretical certainty, these ideas remain in formation, other metaphors may in future be developed and the conditions and nature of contemporary work and practice will continue to evolve. The book does however offer a genuine antidote to a conceptualisation of training, trainees and trainers which dominates so much of the discourse in the disciplines and fields illustrated in the chapters. Through the patchwork of chapters the authors deal with complexity in a way that makes that complexity a compelling and alluring aspect of the landscape of practice which we inhabit and through which we learn. It explores critical concepts in practice-based learning such as identity forming, accountability and the competing and sometimes conflicting voices in the landscape. The book will resonate with readers interested in professional and practice-based learning, for those dealing with issues of learning through boundary crossing and participation in communities of practice. It will engage new scholars and practitioners in this field as well as re-engage those of us who have been around this landscape a few times in the past.

\section{Dr Rachel Lofthouse,}

Head of Teacher Learning and Development, Newcastle University, UK. 